\title{
Utilização de espelho de reflexão frontal aliado ao nivelamento geométrico para determinação de desnível de pontos em ambientes confinados
}

\author{
Use of a geodetic level along with a plain mirror of frontal reflection to aid the definition of height differences in \\ confined environments
}

\author{
Wander da Cruz ${ }^{1}$ \\ Niarkios Luiz Santos de Salles Graça ${ }^{1}$ \\ Pedro Luis Faggion ${ }^{1}$
}

\begin{abstract}
${ }^{1}$ Universidade Federal do Paraná - UFPR. Programa de Pós-Graduação em Ciências Geodésicas. Setor de Ciências da Terra. Departamento de Geomática. Caixa Postal 19001, Cep 81.531-990. Curitiba, PR, Brasil. wander.cruz@ufpr.br, niarkiosnl@hotmail.com,faggion@ufpr.br
\end{abstract}

\begin{abstract}
RESUMO - O propósito deste trabalho é avaliar a utilização de um nível geodésico, em conjunto com um espelho plano de reflexão frontal, na determinação de desníveis de primeira ordem em ambientes confinados. Para isso, foi definido um modelo matemático baseado no princípio da retificação de níveis. Este modelo consiste em determinar a inclinação aplicada ao espelho e assim projetar as leituras realizadas na mira para um plano horizontal comum a todas. A fim de se validar o modelo matemático utilizado foi realizada uma série de experimentos, nos quais se constatou a real possibilidade de utilização da técnica. Porém, erros de até $12 \mathrm{~mm}$ de magnitude foram encontrados, inviabilizando o emprego da técnica proposta para nivelamentos de primeira ordem. Estes erros podem estar associados à modelagem da atitude do espelho, sendo necessário um estudo mais aprofundado. No entanto, a técnica pode ser utilizada em nivelamentos de terceira ordem.
\end{abstract}

Palavras-chave: Nivelamento Geométrico, Espelho Plano, Levantamento de Locais Inacessíveis.

\begin{abstract}
The purpose of this work is to evaluate the use of a geodetic level along with a plain mirror of frontal reflection to aid the definition of height differences in confined environments. To achieve this, a mathematical model based on the principle of level (instrument) rectification was defined. The model consists of determining the tilts applied to the mirror in order to project the readings on the levelling rod to a horizontal plane common to all readings. To evaluate this model a series of experiments was conducted and the feasibility of the proposed technique could be proven. However errors with magnitude up to $12 \mathrm{~mm}$ were found, voiding the technique for first order levelling. Such errors could be associated to modelling the mirror's attitude and a deeper study is required. The technique may be used for third order levelling.
\end{abstract}

Keywords: Geometric Leveling, Plan Mirror, Survey of Inaccessible Places.

\section{INTRODUÇÃO}

Os levantamentos em ambientes de difícil acesso ou confinados podem ser realizados utilizando-se de metodologias que diferem das conhecidas na topografia convencional. Um exemplo disso pode ser encontrado no trabalho desenvolvido por Gonçalves (2009), cujo trecho está transcrito a seguir:

"Atualmente, além dos levantamentos topográficos convencionais, destaca-se a topografia industrial, que tem dentre seus objetivos: a locação com precisão de estruturas e equipamentos, o controle métrico de equipamentos e produtos industriais e o controle de deslocamento de máquinas.

Nesses levantamentos, o método empregado na aquisição de dados é escolhido de acordo com a possibilidade de obtenção dos mesmos. Porém, existem diversas dificuldades que envolvem essa etapa da geração de produtos topográficos, tais como: impossibilidade de medida direta de distância, de ângulos verticais e direções horizontais em face da obstrução existente entre a estação total e o alvo, instabilidade (por vibração do solo) no local do levantamento $e$ impossibilidade de visualização do objeto em estudo.

Para contornar esses problemas, tem se realizado pesquisas buscando desenvolver metodologias que viabilizem a realização de medições que não seriam possíveis utilizando as técnicas tradicionais.

Pensando nisso, essa tese foi concebida com o objetivo de desenvolver um método para determinação de coordenadas de pontos, realizando-se medições de ângulos verticais, direções horizontais e distâncias inclinadas utilizando estação total e acessórios desenvolvidos especificamente para atender esse projeto, 
ou seja, determinar coordenadas de objetos usando um espelho plano para desviar a visada. "

Então, surgiu a proposta de realizar um estudo do comportamento de um nível geodésico juntamente com o espelho plano para se verificar a eficácia de sua utilização em nivelamentos de primeira ordem.

Para minimizar os erros de desvio de visada devido à refração ocorrida na mudança de meio, utilizou-se um espelho plano com espelhamento frontal. Tal modelo de espelhamento não utiliza vidro antes da superfície espelhada, o que faz com que a incidência dos raios luminosos ocorra sem desvios.

Neste estudo foram fixados ganchos metálicos na parede próxima ao Laboratório de Instrumentação Geodésica - LAIG, na Universidade Federal do Paraná, nos locais em que se desejava materializar os pontos a serem levantados. Nos ganchos foi colocada uma mira fabricada com PVC (Policloroetano) e graduada em código de barras, de forma semelhante às utilizadas pelo nível. Esta mira foi desenvolvida no projeto de automação de níveis digitais conduzido em um projeto de doutorado desenvolvido no programa de Pós-Graduação em Ciências Geodésicas da Universidade Federal do Paraná, (ANDOLFATO, 2010)

Com o nível e o espelho foram determinados os desníveis. Os pontos foram dispostos de tal maneira que, para cada par de visadas ou mesmo para cada visada, era necessário inclinar o espelho no eixo horizontal e rotacionar no eixo vertical.

Em seguida determinaram-se os desníveis entre os pontos de forma direta para comparação dos valores obtidos pelos dois diferentes métodos (direto e indireto).

\section{FUNDAMENTAÇÃO TEÓRICA}

\subsection{Espelho de Reflexão Frontal}

A superfície que permite a reflexão de um feixe de luz é denominada de superfície refletora. No estudo em questão, é utilizado um espelho de reflexão frontal, isto quer dizer que o dispositivo utilizado não possui vidro na parte da frente da superfície refletora, como demonstrado na Figura 1.

Esta ausência minimiza o fenômeno da refração, pois o feixe de luz não sofre desvio ao atravessar o vidro (GONÇALVES, 2009).

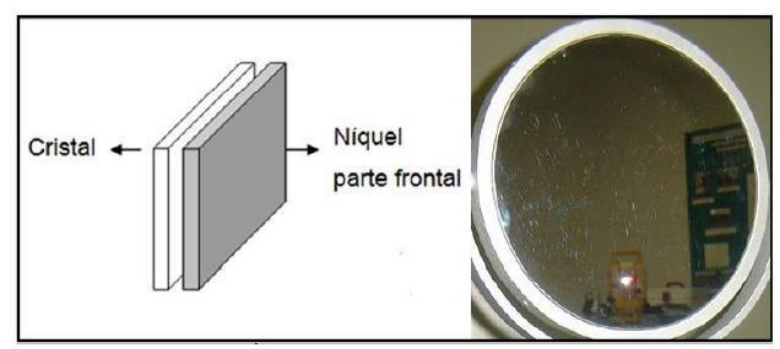

Figura 1 - Espelho de reflexão frontal Fonte: Gonçalves (2009)

Características da reflexão de objetos: a) a distância entre a imagem e o espelho é sempre igual à distância entre o objeto e o espelho;

b) o tamanho da imagem é sempre igual ao tamanho do objeto;

c) os raios incidentes e refletidos permanecem no mesmo plano.

A igualdade do tamanho do objeto e da imagem pode ser demonstrada por meio da Figura 2:

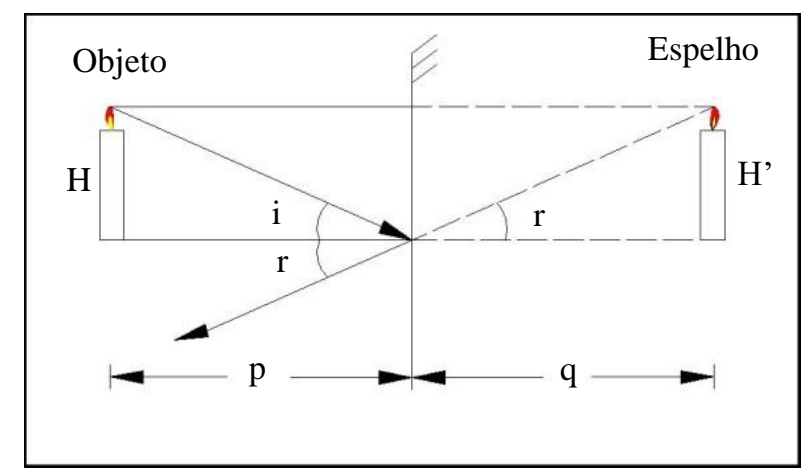

Figura 2 - Objeto e Imagem

Fonte: Adaptado de Schiel (2009).

Onde:

i - ângulo de incidência;

r - ângulo de reflexão;

p - distância do objeto ao espelho;

q - distância da imagem ao espelho;

$\mathrm{H}$ - tamanho do objeto;

H' - tamanho da imagem.

$\mathrm{O}$ raio refletido e o raio incidente pertencem ao mesmo plano (Figura 3), segundo a Lei de Reflexão, sendo o ângulo de incidência (i) igual ao ângulo de reflexão (r) em uma reflexão especular (HALLIDAY et al., 2003).

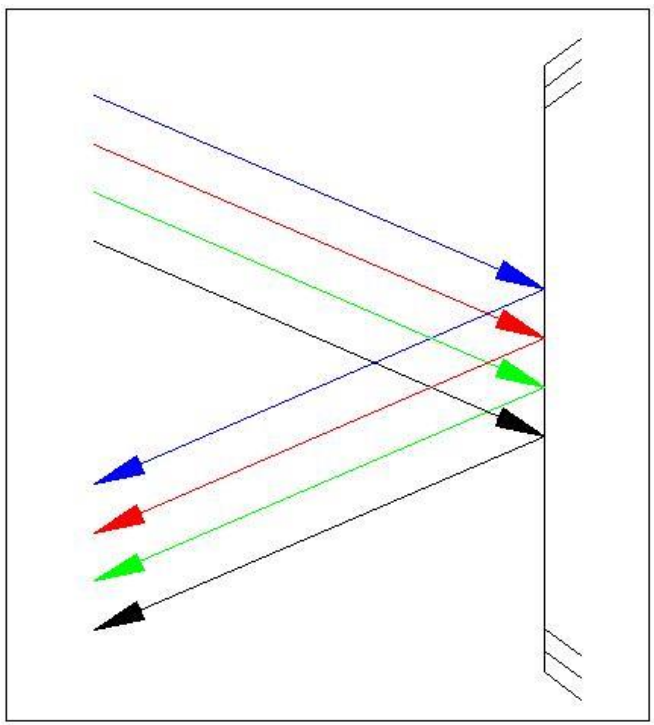

Figura 3 - Reflexão especular

Fonte: adaptado de Halliday et al. (2003) 
Em um espelho comum, conforme mostrado na Figura 4, um raio que atravessa o vidro sofre reflexão e refração até que encontre a superfície pela qual é refletido e, em seguida, sofre estes dois efeitos quando da passagem do vidro para o ar (CORDINI, 1991; GONÇALVES, 2009).

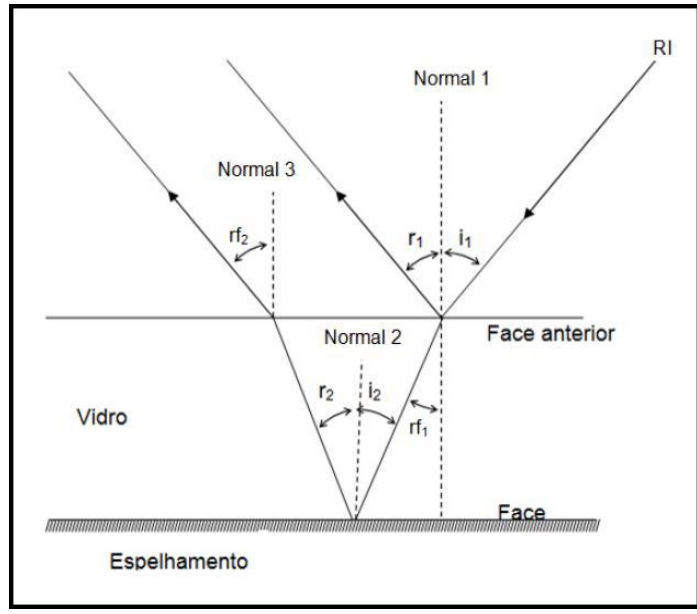

Figura 4 - Dupla Reflexão

Fonte: Gonçalves (2009)

$$
\begin{array}{ll}
\text { Onde: } \\
\mathrm{i} 1 \text { - } & \text { Ângulo de incidência na face anterior; } \\
\mathrm{r} 1 \text { - } & \text { Ângulo de reflexão na face anterior; } \\
\mathrm{rf1}- & \text { Ângulo da primeira refração; } \\
\mathrm{i} 2- & \text { Ângulo de incidência na face posterior; } \\
\mathrm{r} 2- & \text { Ângulo de reflexão na face posterior; } \\
\mathrm{rf2}- & \text { Ângulo da segunda refração; } \\
\text { RI - } & \text { Raio incidente. }
\end{array}
$$

No estudo em questão, como se utiliza a técnica de espelhamento frontal, o efeito da refração dos espelhos comuns não se verifica. $\mathrm{O}$ espelho utilizado é semelhante aos usados em autocolimação, que devem ser opticamente planos e espelhados na superfície frontal, normalmente confeccionados em cristal, podendo também usar superfícies polidas, desde que perfeitamente planas (FAGGION, 1993).

O espelho empregado neste trabalho foi o mesmo utilizado por Gonçalves (2010) em sua tese de doutorado e outros trabalhos publicados. $\mathrm{Na}$ época, verificou-se que, apesar de fabricado por profissional especialista em óptica para lunetas e teodolitos, o referido espelho não resultou perfeitamente plano, o que resulta em possíveis desvios indesejados durante a visada.

\subsection{Níveis Digitais}

Segundo Takalo e Rouhiainen (2004) há algumas diferenças entre o nivelamento digital e o nivelamento convencional:

- Enquanto no nivelamento digital as leituras são automáticas, no nivelamento convencional as leituras são realizadas por operador que se utiliza de ferramentas ópticas, tais como o micrômetro e a placa plano-paralela.
- No nivelamento digital, o olho humano é substituído por uma câmera digital (CCD).

- No método convencional, a leitura da altura é efetuada utilizando apenas uma linha, enquanto o nível digital utiliza várias linhas de código. Com o advento da eletrônica, os equipamentos tornaram-se cada vez menores, mais leves e mais eficientes.

Um sistema para nivelamento digital é composto por um nível óptico, um compensador, uma escala, definida por código de barras, gravado em uma fita de ínvar fixada em uma mira de alumínio, uma câmera CCD e um programa para controle das operações, procedimentos e processos do nível digital (INGENSAND, 1999). O CCD, dispositivo de carga acoplada (charge-coupled device), é um sensor utilizado para captação de imagens. Hoje em dia são muito comuns, por exemplo, nas câmeras fotográficas digitais.

Este nível realiza a leitura da escala gravada no código de barras presente na mira que, por sua vez, fica armazenado no instrumento como sinal de referência. A câmera CCD captura uma imagem da parte superior e inferior do nível horizontal da escala que, posteriormente, é comparada com a escala armazenada na memória do instrumento. Após o processamento desta imagem, o programa fornece a posição vertical (INGENSAND, 1999; TAKALO; ROUHIAINEN, 2004).

Durante a medição, a seção visível da mira no campo de visão é capturada pelo decodificador de linhas e interpretada como sinal de medição. Este é posteriormente comparado com o sinal de referência e, assim, é possível determinar a altura do plano horizontal definido pelo nível e o tamanho da visada (ANDOLFATO, 2010).

Uma das vantagens destes equipamentos reside na eliminação de erros de leitura e, ainda, com a automação na coleta e armazenamento de dados espera-se que os procedimentos manuais de nivelamento geométrico sejam completamente substituídos (RADCLIFFE, 1999).

O primeiro sistema (Wild NA2000), quase totalmente informatizado, foi lançado em 1990 (INGENSAND, 1999). Atualmente são vários os fabricantes atuantes neste mercado, entre eles a Leica, Trimble (Zeiss), Sokkia e Topcon. Isto representa uma gama de opções ao usuário, facilitando a escolha do equipamento a ser utilizado de acordo com a conveniência e exigência do trabalho.

A maioria dos métodos de medições geodésicas utiliza transferência de informação entre duas posições, como é o caso da determinação eletrônica de distância. Este conceito transferido para o processo de nivelamento proporciona a determinação da posição na escala vertical a partir da mira codificada (INGENSAND, 1999).

\section{METODOLOGIA}

Nesta seção será explicada a forma com que os dados foram coletados e também será apresentado o modelo matemático utilizado no processamento destes dados. 
O local escolhido para a coleta de dados relativa ao experimento foi o corredor de acesso ao LAIG. Para materializar os pontos cujos desníveis foram determinados, utilizaram-se suportes fixos na parede ao final deste corredor (Figura 5). Nota-se na imagem o ponto 1 já ocupado pela mira.

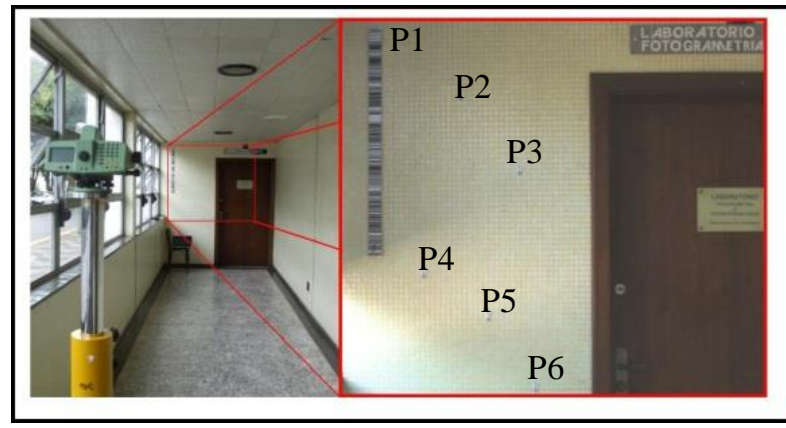

Figura 5 - Local do experimento

Fonte: $\mathrm{O}$ autor.

Primeiramente, para fins de validação do experimento a partir de comparação, os desníveis entre os pontos foram determinados de forma direta.

Para realização das leituras nos pontos fixados na parede, utilizou-se uma mira confeccionada com material PVC (mais leve que a convencional) o que permitiu que os ganchos fixados na parede suportassem seu peso. Tal mira foi utilizada em pesquisas realizadas anteriormente neste laboratório. Para maiores conhecimentos sobre este tipo de mira, recomenda-se Andolfato (2010).

O nível foi instalado de forma equidistante entre os pontos cuja mira de PVC foi posicionada e outra mira convencional utilizada como visada de ré (apoiada sobre o piso), para fins de referência de nível, conforme Figura 6.

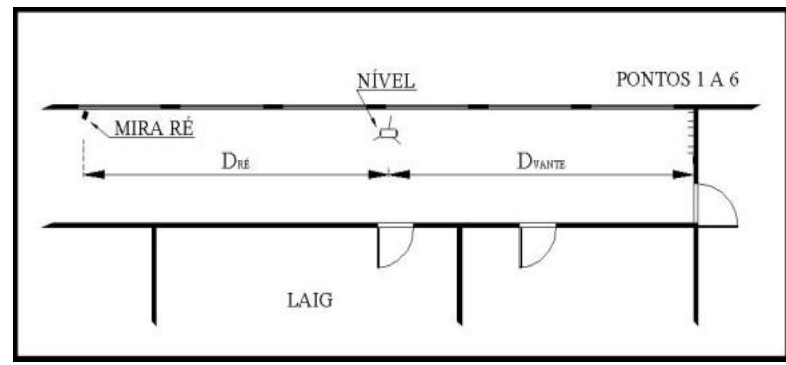

Figura 6 - Croqui do nivelamento direto

Fonte: $\mathrm{O}$ autor

Então, efetuaram-se os cálculos do desnível de cada ponto na parede em relação à mira convencional (referência de nível), utilizando o nivelamento geométrico, que determina o desnível subtraindo o valor da leitura de ré do valor da leitura de vante $(\Delta \mathrm{h}=$ RéVante). Assim, obteve-se o que se pode chamar de cota de cada ponto.

De posse do valor dessas cotas, realizou-se o cálculo do desnível relativo a cada uma delas, através da Eq. 1. Desta forma, obtiveram-se os desníveis entre as cotas que foram utilizados como referência no decorrer deste trabalho.
$\Delta \mathrm{h}_{\mathrm{P}(\mathrm{n}-1)-\mathrm{P}(\mathrm{n})}=\operatorname{cota} \mathrm{P}_{(\mathrm{n})}-\operatorname{cota} \mathrm{P}_{(\mathrm{n}-1)}$

sendo $n=1,2, \ldots, 6$

De posse destes dados, partiu-se para a determinação dos mesmos desníveis a partir da utilização do espelho, como forma indireta de nivelamento.

Esta etapa consistiu em dois procedimentos distintos. O primeiro deu-se com o reposicionamento da mira convencional de ré (utilizada como referência de nível) e o nível (Figura 7).

Como a ideia era que o nível fosse situado em local onde não se permitisse a visada direta dos pontos, a mira foi deslocada conforme se verifica nas Figura 7 e Figura 8.

Na Figura 7 é possível perceber a primeira configuração ajustada para determinar de forma direta o desnível entre a mira de ré e um ponto P1. Isto é necessário para calcular o ângulo de inclinação $\alpha$ do espelho, ou seja, o ângulo formado pelo raio refletido e o plano horizontal, quando o espelho é inclinado para fornecer a imagem do ponto ao operador do nível.

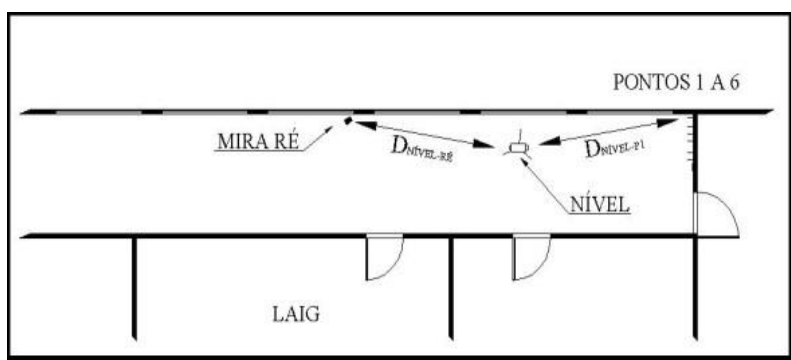

Figura 7 - Determinação do desnível inicial Ré-P1

Fonte: $\mathrm{O}$ autor

Calculado o valor do desnível de P1 pela diferença entre a leitura de ré e vante, a outra configuração foi ajustada a fim de que o nível fosse reposicionado para realizar as leituras indiretas em P1 até $\mathrm{P} 6$, por meio da imagem refletida pelo espelho, conforme se observa na (Figura 8 ).

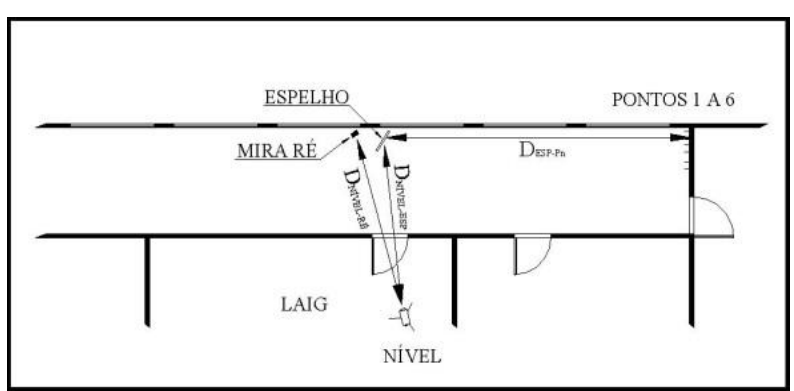

Figura 8 - Determinação indireta de desníveis

Fonte: $\mathrm{O}$ autor

No momento de instalação do nível, é necessário que o fio médio do nível coincida com o eixo horizontal do espelho, ou seja, seu eixo de inclinação. Este cuidado deve ser tomado para que o ângulo de inclinação $\alpha$ seja corretamente calculado. Este ângulo é formado pela distância entre o ponto refletido e o plano horizontal, que 
somente será corretamente projetado se houver tal coincidência (Figura 9).

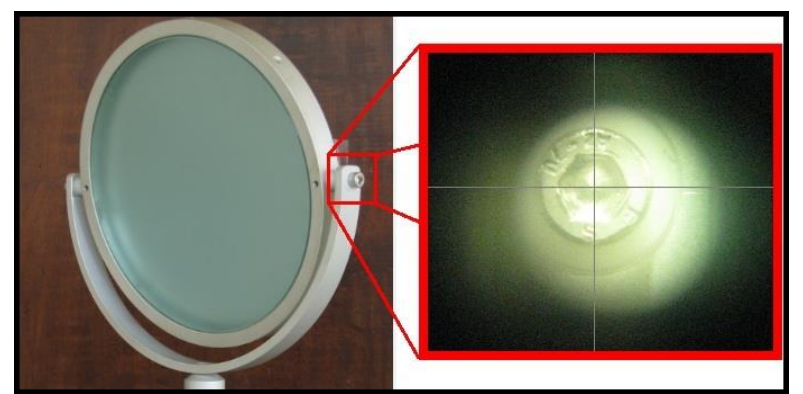

Figura 9 - Fio médio do nível coincidindo com o eixo de inclinação do espelho

Fonte: $\mathrm{O}$ autor

Isto é possível ajustando-se, de forma aproximada, com movimentos verticais, a altura da base do tripé onde o nível é instalado. Em seguida, utilizando os parafusos calantes, realiza-se o ajuste fino da posição vertical do nível.

Finalizado este procedimento, partiu-se para a determinação da inclinação do espelho. Conhecendo-se o valor do desnível Ré-P1 e aplicando o princípio da retificação de níveis, calculou-se a leitura esperada em P1, conforme Eq. 2:

$$
\mathrm{LE}_{1}=\mathrm{L}_{\mathrm{ré}}-\Delta \mathrm{h}_{\text {mira-P1 }}
$$

Onde:

$\mathrm{LE}_{1}$ é a leitura esperada da imagem refletida se estivesse no plano horizontal

$\mathrm{L}_{\text {ré é a leitura realizada na mira de ré. }}$

$\Delta \mathrm{h}_{\text {mira-P1 }}$ é o desnível entre o ponto $\mathrm{P}_{1}$ e a mira de ré, determinado pelo método direto.

De posse dos valores da leitura esperada $\left(\mathrm{LE}_{1}\right)$, leitura realizada $\left(\mathrm{LR}_{1}\right)$ e distância espelho-ponto ( $\left.\mathrm{d}_{\mathrm{esp}-\mathrm{P} 1}\right)$, foi possível calcular a inclinação $\alpha$ (Eq. 3) do espelho (Figura 10):

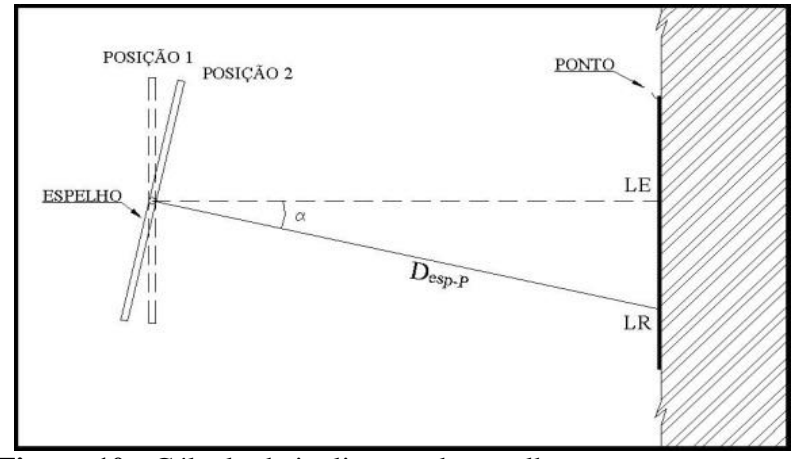

Figura 10 - Cálculo da inclinação do espelho Fonte: $\mathrm{O}$ autor

$$
\alpha=\operatorname{arc} \operatorname{sen}\left(\mathrm{LR}_{1}-\mathrm{LE}_{1}\right) / \mathrm{d}_{\mathrm{esp}-\mathrm{P} 1}
$$

Em seguida, mantendo-se a mesma inclinação do espelho, realizou-se a leitura no ponto 2. Então, com o valor da leitura realizada em $\mathrm{P} 2\left(\mathrm{LR}_{2}\right)$ e a distância
espelho-P2, calculou-se o valor da leitura esperada em P2 (Eq. 4 e Eq. 5).

$$
\begin{aligned}
& \Delta \mathrm{L}_{\mathrm{P} 2}=\mathrm{d}_{\text {esp-P2}} \cdot \operatorname{sen}(\alpha) \\
& \mathrm{LE}_{2}=\mathrm{LR}_{2}-\Delta \mathrm{L}_{\mathrm{P} 2}
\end{aligned}
$$

Foram calculados os desníveis P1-P2 e Ré-P2 utilizando as equações Eq. 6 e Eq. 7 respectivamente:

$$
\begin{aligned}
& \Delta \mathrm{H}_{\mathrm{P} 1-\mathrm{P} 2}=\mathrm{LE}_{1}-\mathrm{LE}_{2} \\
& \Delta \mathrm{H}_{\text {Ré-P2 }}=\Delta \mathrm{h}_{\text {mira-P1 }}-\mathrm{LE}_{2}
\end{aligned}
$$

Repetiu-se o procedimento para todas as leituras possíveis com a mesma inclinação do espelho em relação a P1.

Para avistar todos os pontos, houve necessidade de alterar a inclinação e rotação do espelho. Para o cálculo da nova inclinação é necessário um ponto comum nas duas leituras. Os desníveis entre os pontos visados foram calculados de forma análoga à mostrada nas Eqs. 2 a 5 .

\section{RESULTADOS}

Várias posições foram ocupadas com o nível e com o espelho a fim de obter um número elevado de observações. A seguir, na Tabela 1, são apresentadas as 6 séries de observações com as respectivas distâncias entre o nível e o espelho e entre o espelho e os pontos fixos na parede, observados de forma indireta.

Tabela 1 - Distâncias utilizadas nos levantamentos.

\begin{tabular}{ccc}
\hline Série & $\begin{array}{c}\text { Dist. Nível - } \\
\text { Espelho (m) }\end{array}$ & $\begin{array}{c}\text { Dist. Espelho - } \\
\text { Pontos (m) }\end{array}$ \\
\hline 1 & 3,82 & 2,16 \\
2 & 7,67 & 2,37 \\
3 & 2,00 & 3,44 \\
4 & 1,93 & 3,42 \\
5 & 6,40 & 24,35 \\
6 & 4,43 & 14,16 \\
\hline
\end{tabular}

As séries 1 a 4 apresentaram resultados muito divergentes daqueles obtidos pelo método direto de nivelamento. Isto ocorreu porque as observações destes pontos aconteceram depois de inclinar e/ou rotacionar o espelho.

Conforme explicado na metodologia, o modelo matemático adotado apoiou-se somente na questão da inclinação, ou seja, no movimento do espelho em relação ao plano horizontal.

Num primeiro momento, a rotação em torno do eixo vertical não deveria influenciar nos resultados, porque não interfere no ângulo de inclinação. 
Neste sentido, surgiram questionamentos sobre a forma de se modelar e compensar a inclinação do espelho. Decidiu-se, então, utilizar um número maior de pontos e gerar mais observações para entender como o processo todo se comporta. Para isso foram colocados pontos auxiliares (7 a 15) entre os pontos principais ( 1 a 6 ).
Na Figura 11 a seguir é apresentado um gráfico com as diferenças entre as cotas dos pontos, resultantes das observações diretas e indiretas.

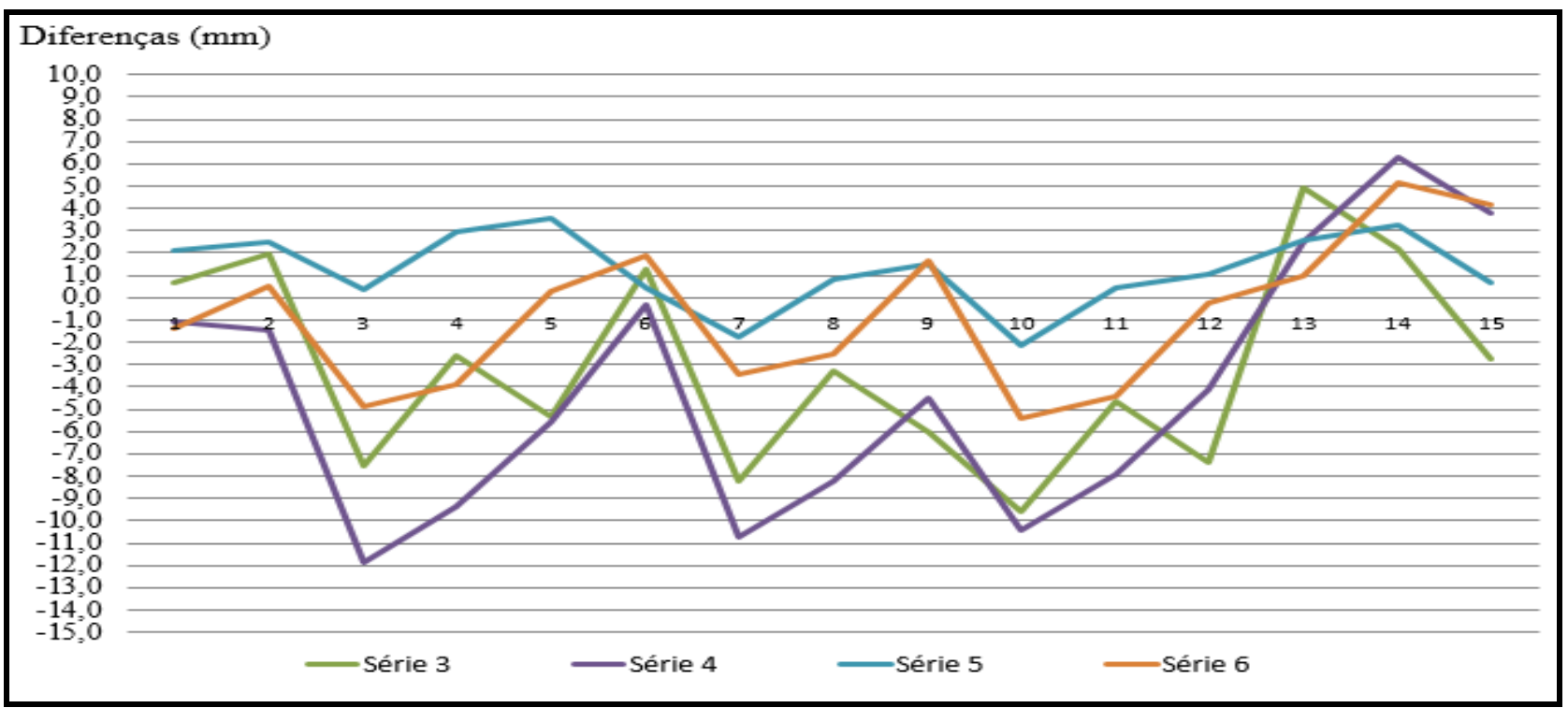

Figura 11 - Diferença entre os desníveis para cada série de leitura. Fonte: $\mathrm{O}$ autor

Para o ponto 1, a diferença entre as cotas observadas de forma direta e indireta resultou em aproximadamente $1 \mathrm{~mm}$ para as séries 3,4 e 6 e aproximadamente $2 \mathrm{~mm}$ para a série 5 (as séries referemse aos posicionamentos de nível e espelho, conforme Tabela 1). O ponto 2 apresentou a maior diferença (pouco mais de $2 \mathrm{~mm}$ ) para as observações realizadas na série 5 .

A partir do ponto 3 nota-se um comportamento desordenado de valores muito discrepantes das observações diretas. Na série 4 de observações indiretas, o ponto 3 apresentou divergência de $-12 \mathrm{~mm}$ e o ponto 14 divergiu em $+6 \mathrm{~mm}$.

Assim, pode-se perceber uma amplitude de $18 \mathrm{~mm}$ de diferença entre as cotas observadas direta e indiretamente para a série 4, cuja configuração de distâncias nível-espelho e espelho-pontos foi de 1,93m e $3,42 \mathrm{~m}$, respectivamente. Esta série apresentou a necessidade de inclinar e rotacionar diversas vezes o espelho de modo a avistar os pontos refletidos.

Já na série 5, cujas distâncias nível-espelho e espelho-pontos foram de $6,40 \mathrm{~m}$ e $24,35 \mathrm{~m}$, respecitamente, uma gama maior de pontos pode ser avistada pelo observador, sem a necessidade de muitas rotações e inclinações.

De acordo com o gráfico, percebe-se que esta foi a série com menor amplitude de diferenças $(5 \mathrm{~mm})$, com destaque para os piores casos percebidos no ponto 5 , com diferença de pouco mais de $3 \mathrm{~mm}$ e no ponto $7 \mathrm{com}$ diferença de aproximadamente $2 \mathrm{~mm}$.

A série 6, cuja distâcia espelho-pontos foi de $14,16 \mathrm{~m}$, apesar do comportamento um pouco mais linear, teve amplitude de $10 \mathrm{~mm}$ de diferença, verificado no ponto 10 (diferença de $-5 \mathrm{~mm}$ ) e no ponto 14 (diferença de $+5 \mathrm{~mm})$.

As séries 1 e 2 foram suprimidas do gráfico porque apresentaram diferença entre cotas de até $44 \mathrm{~mm}$.

\section{CONCLUSÕES E RECOMENDAÇÕES}

Após analisar os valores resultantes das séries 1 e 2 constatou-se que existe uma variação também quando o espelho é girado sobre o eixo vertical e não somente quando é inclinado.

Aumentando a distância espelho-pontos não houve necessidade de realizar giro no espelho, o que demonstrou sensível melhora nos resultados obtidos, já que a diferença entre os desníveis foi reduzida para menos de quatro milímetros.

Conforme citado na revisão teórica, o espelho não se apresenta perfeitamente plano, apesar dos cuidados na sua fabricação. Tais imperfeições também podem ter contribuído para as discrepâncias apresentadas.

Conclui-se que a utilização de espelhos para nivelamentos de pontos com acessibilidade difícil é uma técnica promissora. Porém, considerando os resultados obtidos, verifica-se que ainda não é possível realizar nivelamentos de primeira ordem.

Por isso, recomenda-se sua utilização em trabalhos que exijam um rigor um pouco menor como na determinação de desníveis considerados de terceira ordem ou aqueles empregados na construção civil.

Recomenda-se a continuidade do assunto, realizando-se juntamente com o nivelamento, um estudo sobre a relação entre a variação da posição do espelho e 
amplitude dos erros. Para isso, deve-se aliar a determinação da atitude do espelho em cada posição ocupada.

\section{AGRADECIMENTOS}

Este trabalho tem a cooperação e suporte da Universidade Federal do Paraná, através do Curso de PósGraduação em Ciências Geodésicas e do Departamento de Geomática, que colocam a disposição as instalações e equipamentos do Laboratório de Instrumentação Geodésica (LAIG).

$\mathrm{O}$ apoio financeiro para a realização dos estudos foi disponibilizado através de bolsa pelo CNPq.

\section{REFERÊNCIAS BIBLIOGRÁFICAS}

ANDOLFATO, S. H. D. Sistema de automação de níveis digitais. Tese (Doutorado) - Curso de Pós-Graduação em Ciências Geodésicas - UFPR. Curitiba, 2010.

CORDINI, J. Determinação do erro cíclico em distanciômetros eletrônicos. Curitiba, 1991. 138p. Dissertação (Mestrado) - Curso de Pós-Graduação em Ciências Geodésicas, Universidade Federal do Paraná.

FAGGION, P. L. Contribuição para a Implantação de um Sistema de Aferição de Miras na Universidade Federal do Paraná. Curitiba, 1993 (Dissertação de Mestrado). Curso de Pós-Graduação em Ciências Geodésicas, Universidade Federal do Paraná.

GONÇALVES, M. L. A. M. Determinação indireta de coordenadas planorretangulares utilizando estação total e espelho plano. Boletim de Ciências Geodésicas, Curitiba, v. 16, no 4, p.491-502, out-dez, 2010.

GONÇALVES, M. L. A. M. Determinação indireta de coordenadas topográfica utilizando estação total $e$ espelho. Tese (Doutorado) - Curso de Pós-Graduação em Ciências Geodésicas - UFPR. Curitiba, 2009.

HALLIDAY, D.; RESNICK, R.; WALKER, J. Fundamentos de Física - Óptica e Física Moderna, 7. ed. Rio de Janeiro: LTC, 2003.

INGENSAND, H. The evolution of digital levelling techniques - limitations and new solutions. In Lilje M (ed.): The importance of heights. FIG, Gävle, Sweden: 59-68. 1999.

LEICA. Informe Técnico de los niveles digitales NA2002 e NA3003. Informe Técnico, Leica, 2003.

RADCLIFFE, D. Feature: How digital levels work. Professional Surveyor, Volume 19, Number 5, June 1999.

TAKALO, M., ROUHIAINEN, P. Development of a System Calibration Comparator for Digital Levels in Finland. Nordic Journal of Surveying and Real Estate Research, Vol. 1. 2004. 